\title{
Phytomedicine: Alternative safe vehicles on the pathway of diabetes mellitus
}

\author{
Divya Singh and Sanjeev Singh • \\ Department of Biotechnology, School of Bioengineering and Biosciences, Lovely Professional University, Phagwara-144411, Punjab, India
}

\section{Article Info}

Article history

Received 13 March 2021

Revised 29 April 2021

Accepted 30 April 2021

Published online 30 June 2021

\section{Keywords}

Diabetes mellitus

Antidiabetic drugs

Side effects

Antidiabetic medicinal plants

Phytomedicine

\begin{abstract}
Diabetes mellitus, a metabolic disorder, is one of the most serious threat to public health worldwide which has no permanent remedy. The treatment simply relies on some antidiabetic drugs whose longterm treatment can lead to several side effects such as hypoglycemia, weight gain, hypersensitivity. Therefore, to reduce the side effects and to improve the quality of life for diabetic patients, several evidences have showed that some natural products and herbal medicines possess antidiabetic properties with fewer side effects which may work as potential drug to treat diabetes diseases. Hence, this paper covers some medicinal plants and their constituents which have shown its potential and beneficial effect for the treat the effect of diabetes mellitus and regulation of blood glucose along with their other health benefits.
\end{abstract}

\section{Introduction}

Diabetes mellitus is developed due to long term existence of hyperglycemia in the body. Increased blood glucose levels above the standard range lead to hyperglycemia and this situation may arise due to defects in insulin secretion, action, or both (WHO, 2002; Ota and Ulrih, 2017).

The number of people with diabetes is steadily increasing due to factors such as age, obesity, physical inactivity, and unhealthy diet, including alcohol and tobacco consumption (Choudhury et al., 2018; Wild et al., 2004). By 2030, it is estimated that the number of people living with diabetes would have doubled to about 366 million (Wild et al., 2004). If diabetes is not treated, it can lead to a number of complications, some of which can be fatal, if blood glucose levels rise too high. Vascular complications, which may be both macrovascular and microvascular conditions, are one of the most dreadful effects of diabetes. Nephropathy, retinopathy, and neuropathy are examples of microvascular complications, while cardiovascular disorders are an example of macrovascular complications (Forbes and Cooper, 2013).

Natural agents of plants can be used not only for dietary purposes, but also as a treatment for a variety of ailments. Herbal medicine, also recognized as phytomedicine, is formulated by using of various plants parts for medicinal purposes, including flowers, fruits, seeds, leaves, bark, and roots (Ehrlich, 2013).

\section{Corresponding author: Mr. Sanjeev Singh}

Assistant Professor, Department of Biotechnology, School of Bioengineering and Biosciences, Lovely Professional University, Phagwara-144411, Punjab, India

E-mail: sanjeev03genome@gmail.com

Tel.: +91-8437160383

Copyright (C) 2021 Ukaaz Publications. All rights reserved.

Email: ukaaz@yahoo.com; Website: www.ukaazpublications.com
Since the control of diabetes is an important area of concern along with improving quality of life for diabetic patients. This paper covers the use of medicinal plants and herbs for the treatment of diabetes mellitus to avoid the currently used medications that can cause several side effects.

\section{Conventional medicines used for diabetes and the problems associated}

Diabetes can be managed with a combination of nutritional and lifestyle changes along with medications. Insulin therapy and orally administered drugs such as insulin analogues, dipeptidyl peptidase4 inhibitors, sulphonylureas, biguanides, thiazolidinediones, $\alpha$-glucosidase inhibitors are currently used therapeutic strategies for diabetes mellitus where different categories have a different mechanism of action to decrease the increased glucose level (Li et al., 2017).

The different classes of antidiabetic drugs along with their side effects are shown in Table 1. However, side effects due to the longterm treatment of available antidiabetic drugs have increased the need and demand of such agents that are efficacious, produce less side effects and are affordable (Choudhury et al., 2018).

\section{Natural products and herbs for diabetes mellitus treatment}

To some degree, weight loss, increased physical activity, and other lifestyle improvements may be beneficial for the treatment of diabetes, but patient acceptability and compliance are low (Beccuti et al., 2017). As a result, antidiabetic medications are now commonly used, but they may have a variety of harmful side effects, including hypoglycemia, weight gain, allergic reactions, and heart problems which limits their use. Several studies have shown that the active ingredients in the natural products and herbs have antidiabetic properties while having lower toxicity and side effects (Xu et al., 2018). 
Table 1: Classes of antidiabetic drugs and their side effects. (Nuss and Wagman, 2000; Ganie and Kotwal, 2012; Tripathi, 2013; Wu et al., 2014)

\begin{tabular}{|c|c|}
\hline Class & Side effects \\
\hline \multirow[t]{3}{*}{ Sulfonylureas } & - Hypoglycemia \\
\hline & - Weight gain \\
\hline & - Hypersensitivity \\
\hline \multirow[t]{4}{*}{ Meglitinide analogues } & - Mild headache \\
\hline & - Weight gain \\
\hline & - Dyspepsia \\
\hline & - Arthralgia \\
\hline \multirow[t]{6}{*}{ Biguanides } & - Abdominal pain \\
\hline & - Anorexia \\
\hline & - Bloating \\
\hline & - Nausea \\
\hline & - Mild diarrhoea \\
\hline & - Tiredness \\
\hline \multirow[t]{2}{*}{ Thiazolidinediones } & - Weight gain \\
\hline & - Risk of bladder cancer \\
\hline \multirow[t]{3}{*}{ GLP-1 receptor agonists } & - Nausea \\
\hline & - Vomiting \\
\hline & - Diarrhoea \\
\hline \multirow[t]{2}{*}{$\alpha$-Glucosidase inhibitors } & - Flatulence \\
\hline & - Abdominal discomfort \\
\hline \multirow[t]{3}{*}{ DPP-4 inhibitors } & - Nausea \\
\hline & - Headache \\
\hline & - Allergic reactions \\
\hline
\end{tabular}

However, selecting desired herb depends on some factors such as the stage of progression of the disease, comorbidities associated, availability and the safety profile of the herb (Choudhury et al., 2018).

The natural products or herbs that are known to show some antidiabetic properties are:

\subsection{Allium sativum L.}

It is known as garlic and belongs to the Amaryllidaceae family (Iciek et al., 2009). It has been observed that the antidiabetic medicinal potential of $A$. sativum is more than glibenclamide (Gebreselema and Mebrahtu Gebreyohannes, 2013). Alliin, allicin, ajoene, diallyl trisulfide, diallyl sulphide, S-allyl cysteine, diallyl disulfide, and allyl mercaptan are the main active ingredients present in garlic that have antidiabetic potential (Bayan et al., 2014; Padiya and Banerjee, 2013).

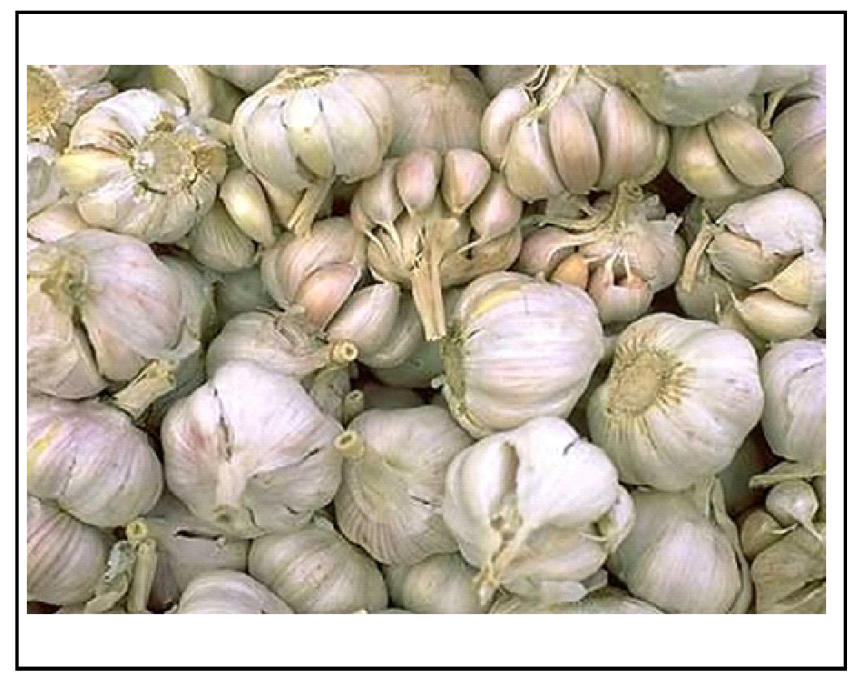

Figure 1: Allium sativum L. Bulbs (Hammel, 1999).

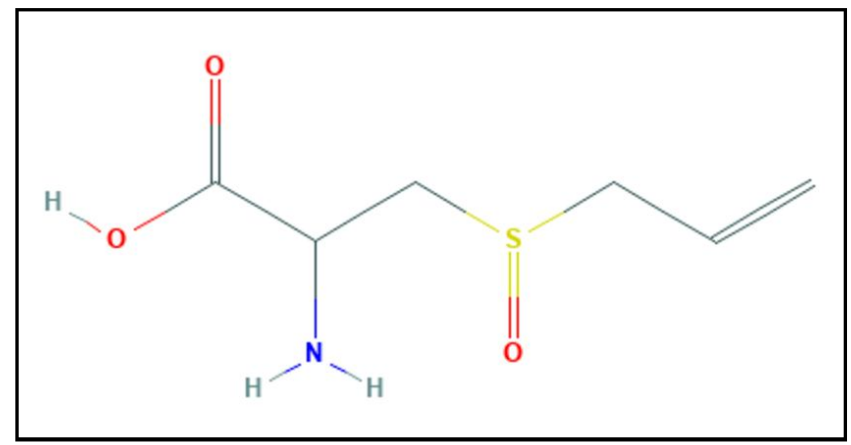

Figure 2: Structure of alliin (NCBI, 2021).

\subsubsection{Mode of action}

Some properties of garlic that are involved in the antidiabetic potential are antiglycation, hyperinsulinemia, hypoglycemia, hypocholesterolemia, hypotriglyceridemia (Thomson et al., 2015). According to another study, other form of garlic compounds such as juice, oil of ripe bulb and its ethanolic extract decreased blood glucose by inducing insulin secretion from pancreatic cells. It is also established that regular administration of garlic extract $(100$ $\mathrm{mg} / \mathrm{kg}$ ) through oral route helped in reducing glucose level in plasma with rising insulin (Andrade-Cetto and Wiedenfeld, 2004).

It also promotes total antioxidant levels along with catalase activity along (Thomson et al., 2015) with other therapeutic effects such as decreasing the pressure of blood as well as the level of cholesterol (Lakshmi et al., 2012).

\subsection{Citrullus colocynthis L.}

It is a member of the Cucurbitaceae family and was found to be effective for diabetes. It was found that saponins, flavanoids, terpenoids, alkaloids, anthranol, steroids are present in C. colocynthis (Najafi et al., 2010; Gill et al., 2011; Rodge and Biradar, 2012; Elgerwi et al., 2013; Jayaraman and Christina, 2013; Talole et al., 2013; Uma and Sekar, 2014). 


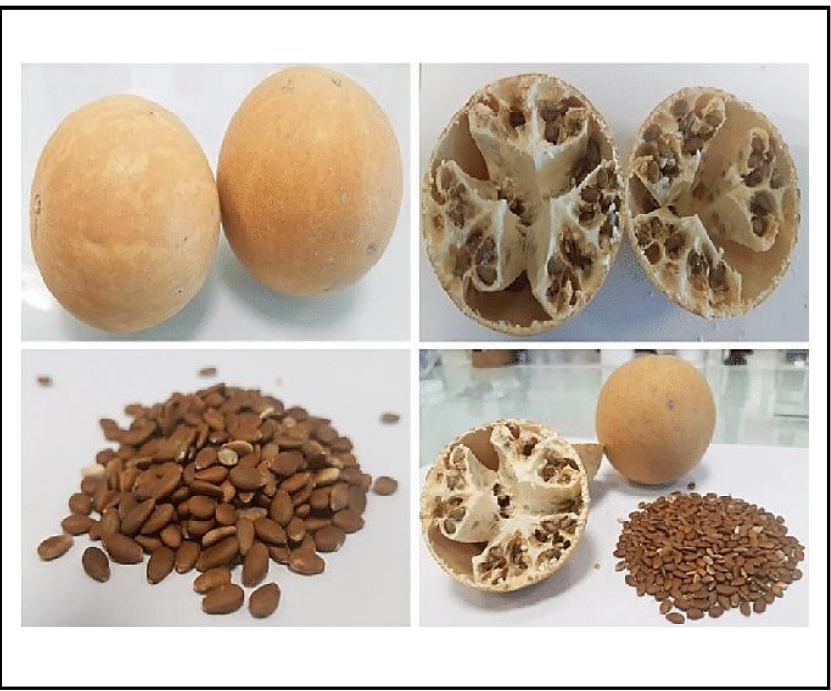

Figure 3: Citrullus colocynthis L. fruit and seeds (Kouadri et al., 2018).

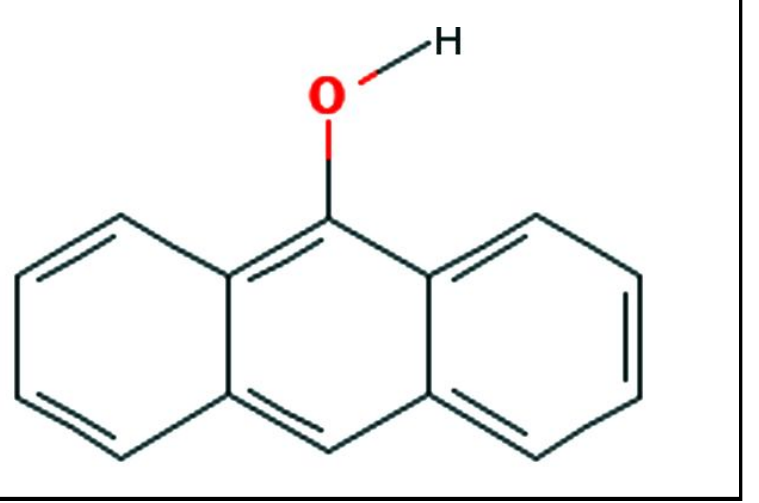

Figure 4: Structure of anthranol (NCBI, 2021).

\subsubsection{Mode of action}

Following administration of a $200 \mathrm{mg} / \mathrm{kg}$ dose of $C$. colocynthis extract, it was discovered that the aqueous extract of the seed was effective in lowering glucose levels and raising serum insulin, while the hydro-alcoholic extract of the peel increased glucose levels and decreased serum insulin. The seed of the fruit is the most effective part for the treatment of type 2 diabetes, while its peel is harmful for diabetes treatment (Ahangarpour and Oroojan, 2013). Its actualanti-diabetic mechanism is still not very clear butaccording to a study $C$. colocynthis effects isolated pancreatic islets in a similar way to that of insulin (Nmila et al., 2000; Barghamdi et al., 2016).

\subsection{Mangifera indica $\mathrm{L}$.}

It is commonly known as mango and belongs to the family Anacardiaceae. The leaves of mango are known to have shown antidiabetic activity (Dwivedi and Daspaul, 2013). The natural Cglucoside xanthone mangiferin is known to be found in several M. indica parts such as leaves (Desai et al., 1966), fruits (El Ansari et al., 1971), stem bark (Bhatia et al., 1967; El Ansari et al., 1967).

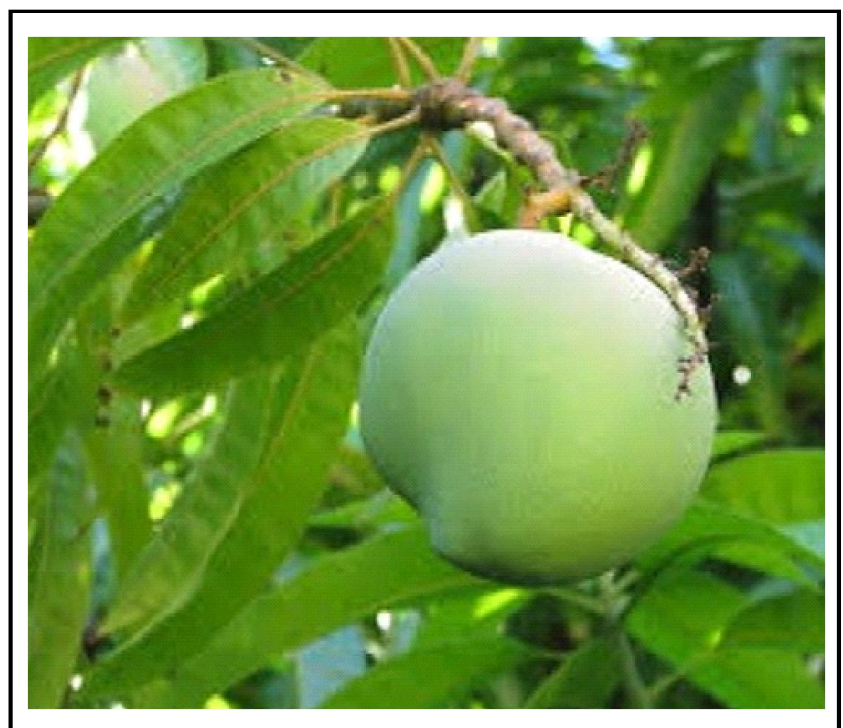

Figure 5: Mangifera indica L. fruit and leaves (Parvez, 2016).<smiles>[2H][C@@]1(c2c(O)cc3oc4cc(O)c(O)cc4c(=O)c3c2O)O[C@H](CO)[C@@H](O)[C@H](O)[C@H]1O</smiles>

Figure 6: Structure of mangiferin (NCBI, 2021).

\subsubsection{Mode of action}

It was observed that the aqueous extract of the leaves was effective in decreasing glucose level in normoglycaemic and glucose induced hyperglycemia (Aderibigbe et al., 2001). There was no impact on blood glucose levels in normoglycaemic or STZ-induced diabetic rats when mango leaves were given orally ( $1 \mathrm{~g} / \mathrm{kg})$, but its antidiabetic activity was observable when the extract and glucose was administrated at the same time. This happens due to reduced intestinal absorption of glucose (Aderibigbe et al., 1999).

Along with the antidiabetic activity, there was also an observed increase in the antioxidant activity. Also, there was an improvement seen in the glomerular filtration rate and microalbuminuria level with this treatment (Aderibigbe et al., 1999).

\subsection{Allium cepa $\mathrm{L}$.}

A. cepa is an herb that belongs to the family Amaryllidaceae and is generally known as onion. Dried bulb or fresh parts of the plants are used which are commercially cultivated across the world (WHO, 1999). 


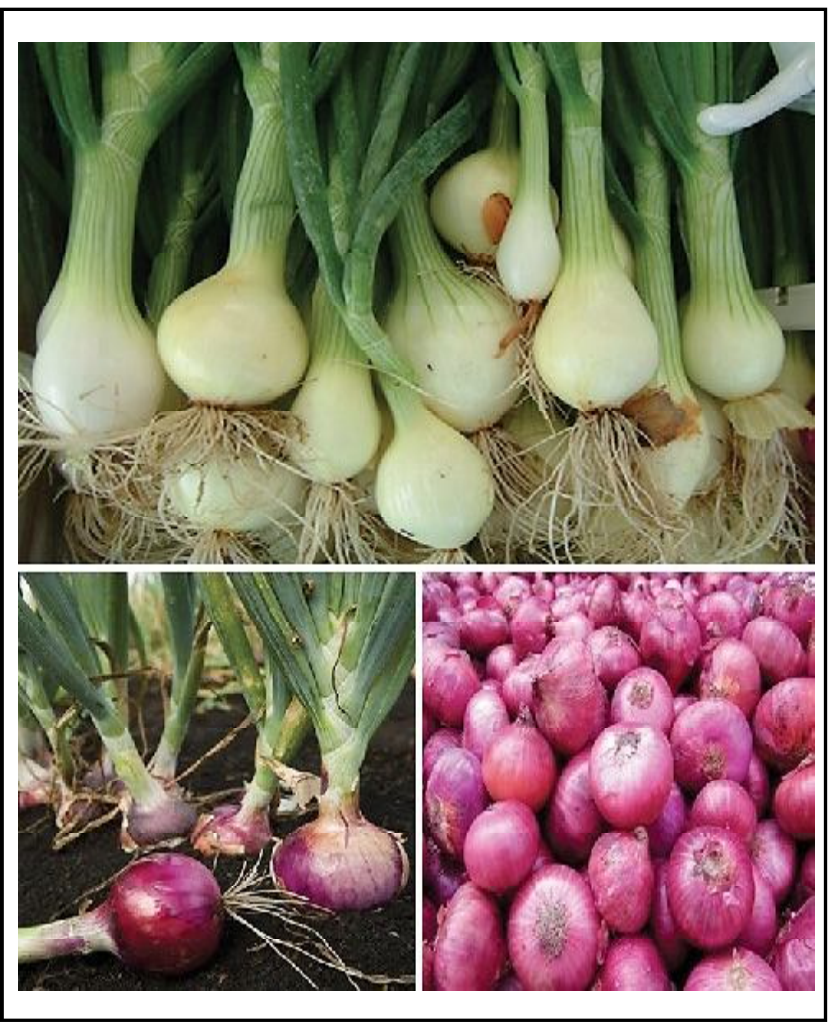

Figure 7: Allium cepa L. bulbs (Upadhyay, 2016).

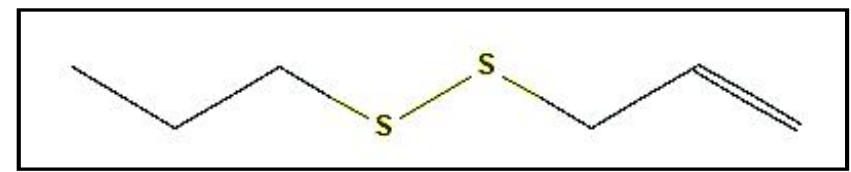

Figure 8: Structure of allyl propyl disulphide (NCBI, 2021).

\subsubsection{Mode of action}

It contains the chemical ingredient allyl propyl disulphide (APDS), which prevents insulin destruction by the liver and stimulates insulin production by the pancreas, raising insulin concentration and lowering blood glucose levels (Verma et al., 2018). Small dose of onion $(100 \mathrm{~g} / \mathrm{day})$ was given to the patient through oral route and its significant anti-diabetes effect was identified with fasting blood glucose levels dropping by about $89 \mathrm{mg} / \mathrm{dL}$ in type 1 diabetes patients and in the case of type 2 diabetes mellitus patient around $40 \mathrm{mg} / \mathrm{dL}$ decrement was recorded (Eldin et al., 2010; Jevas, 2011). It was found that $300 \mathrm{mg} / \mathrm{kg}$ of onion are most useful dose for the treatment of hyperglycemia and hyperlipidemia (Verma et al., 2018).

\subsection{Momordica charantia L.}

It is a climbing plant belonging to the Cucurbitaceae family and commonly referred to as bitter gourd or bitter melon. The bitter taste of all parts of the plant, has a rough texture that resembles a cucumber (Ota and Ulrih, 2017; Grover and Yadav, 2004). Extract from the fruit $(200 \mathrm{mg} / \mathrm{kg}$ ) shows hypoglycemic behaviour (Verma et al., 2018). Sterols, triterpenes and bioactive protein are the key chemical constituents (Yuwai et al., 1991) along with lectin, which has an activity like insulin.

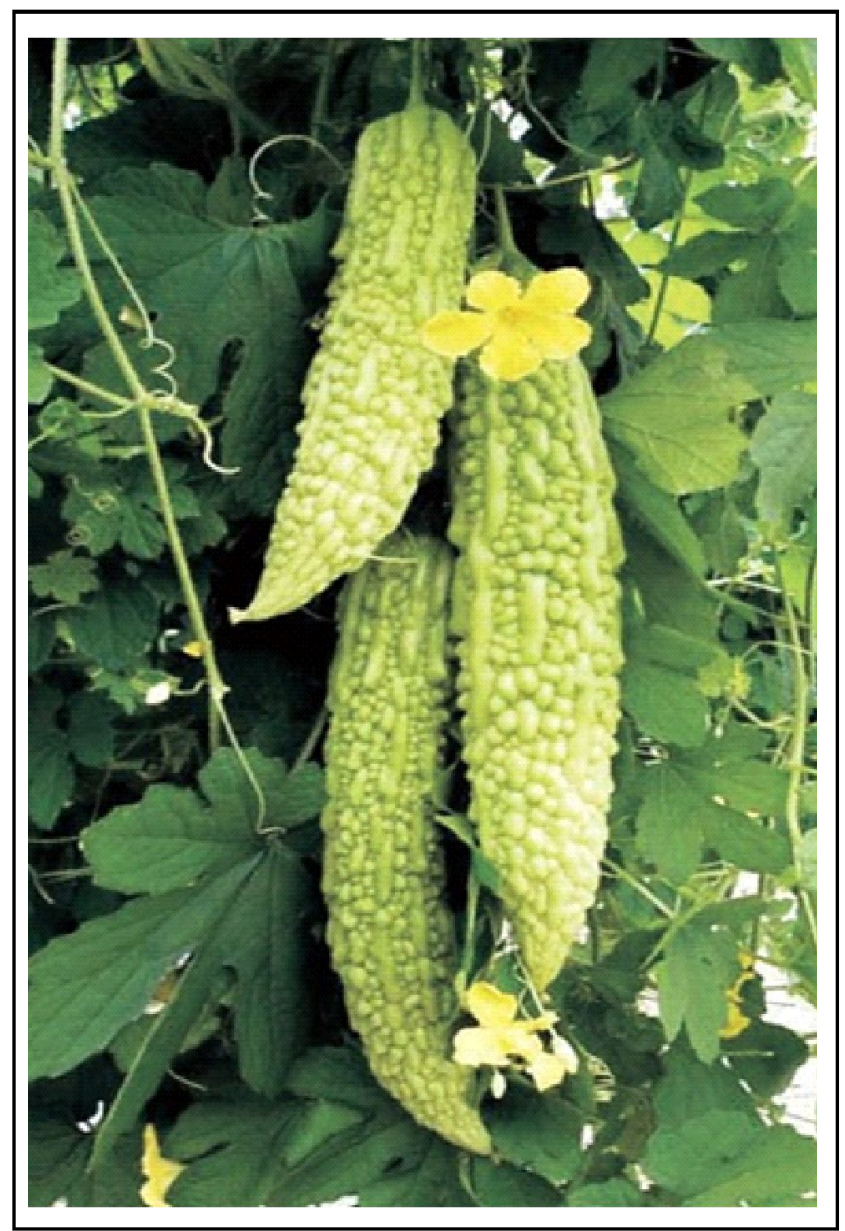

Figure 9: Momordica charantia plant (Joseph and Jini, 2013).

\subsubsection{Mode of action}

Lectin, which is related to insulin receptors, is a non-protein. By acting on peripheral tissues, this lectin lowers the amount of blood sugar (Khan et al., 2014). Intestinal glucose absorption can be blocked (Grover and Yadav, 2004; Chaturvedi, 2012), main glucogenic enzymes suppressed (Shibib et al., 1993) and hepatic gluconeogenesis reduced (Tsai et al., 2012). The mode of action involves using adipocytes and skeletal muscle to induce glucose. In addition, bitter melon extract decreases the impaired signaling of insulin as well as provides pancreatic beta cells with defense. Upregulation of the expression of peroxisome proliferator activated gamma receptor (PPAR $\gamma$ gene), which also involves one of bitter melon's pathways for antidiabetic effects in glucose metabolism (Choudhury et al., 2018; Xu et al., 2015; Joseph and Jini, 2013).

\subsection{Carica papaya $\mathbf{L}$.}

Generally known as papaya, it belongs to the Caricaceae family. The extract of seeds and leaves indicates a lower blood sugar level and a lower lipid level in the body (Giovannini et al., 2016). It was found that leaves and fruits of $C$. papaya contains $\beta$-carotene, lycopene, anthraquinones glycoside (Varisha et al., 2013). 


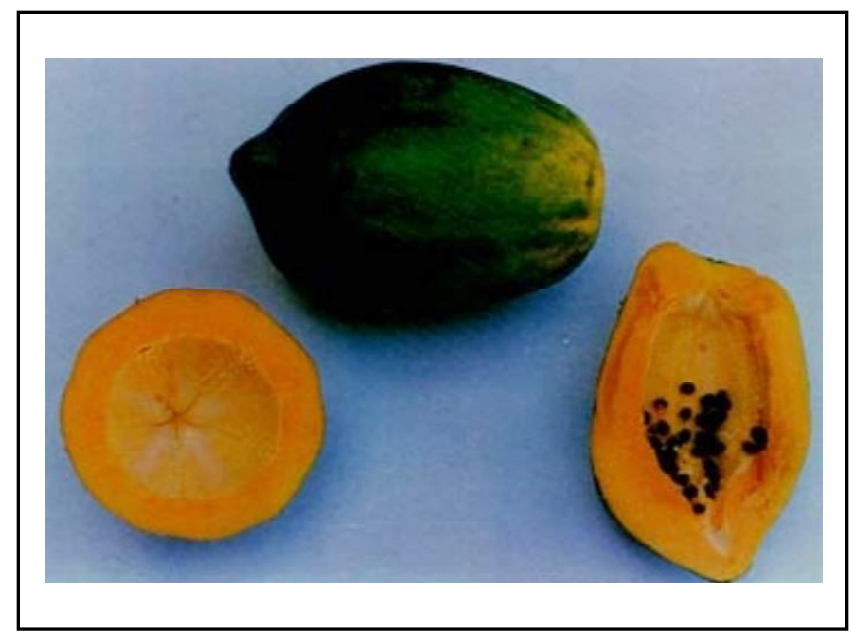

Figure 10: Carica papaya L. fruits (Krishna et al., 2008).

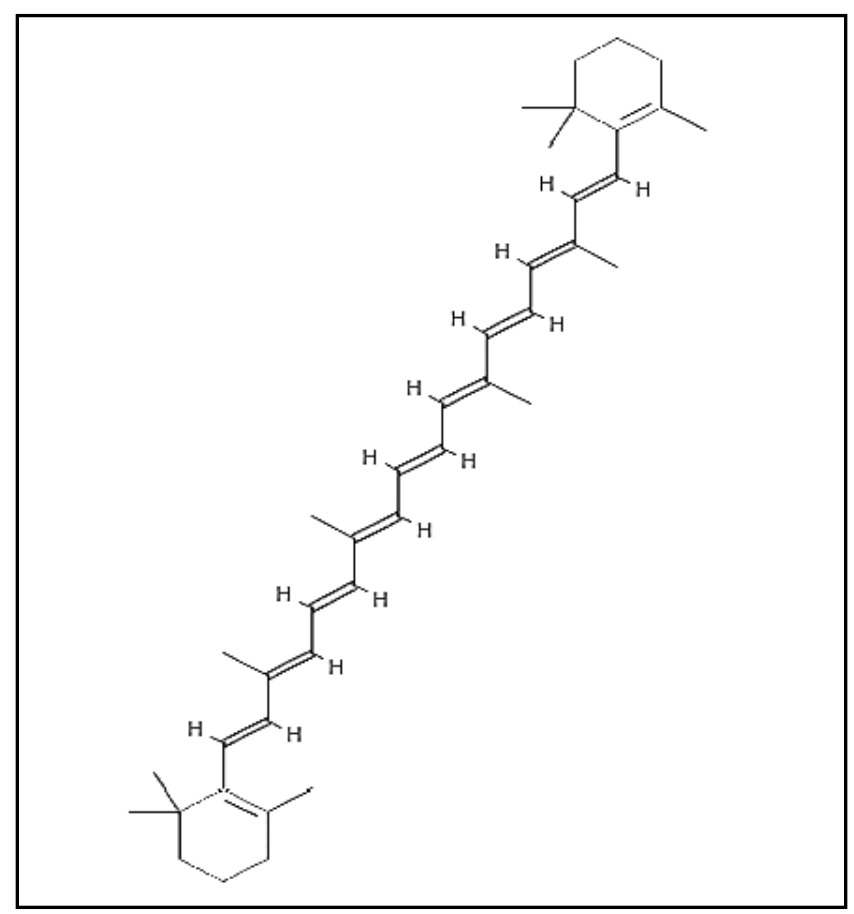

Figure 11: Structure of $\beta$-carotene (NCBI, 2021).

\subsubsection{Mode of action}

Carica papaya's aqueous extract $(0.75 \mathrm{~g}$ and $1.5 \mathrm{~g} / 100 \mathrm{ml})$ substantially decreased blood glucose levels. It also reduced blood levels of cholesterol, triacylglycerol and aminotransferases. In diabetic rats, low plasma insulin levels did not improve after treatment, but they increased significantly in nondiabetic animals. In nondiabetic treated animals, pancreatic islet cells were regular, whereas in diabetic-treated rats, papaya could aid islet regeneration, which is manifested as cell size preservation. In the liver of treated rats with diabetes, papaya, as well as the accumulation of glycogen and lipids, prevented hepatocyte disruption. Eventually, the antioxidant influence of papaya extract has been observed in diabetic rats, too (Jurez-Rojop et al., 2012).

\subsection{Catharanthus roseus $\mathrm{L}$.}

It is called Vinca roseus, which belongs to the Apocynaceae family. Oral administration of a dosage of $500 \mathrm{mg} / \mathrm{kg}$ of methanolic leaf and twig extract indicates a drop in blood sugar levels (Malvi et al., 2011). The key biological ingredients for the hypoglycemic effect are found to be vindoline, tetrahydroalstonine and catharanthine.

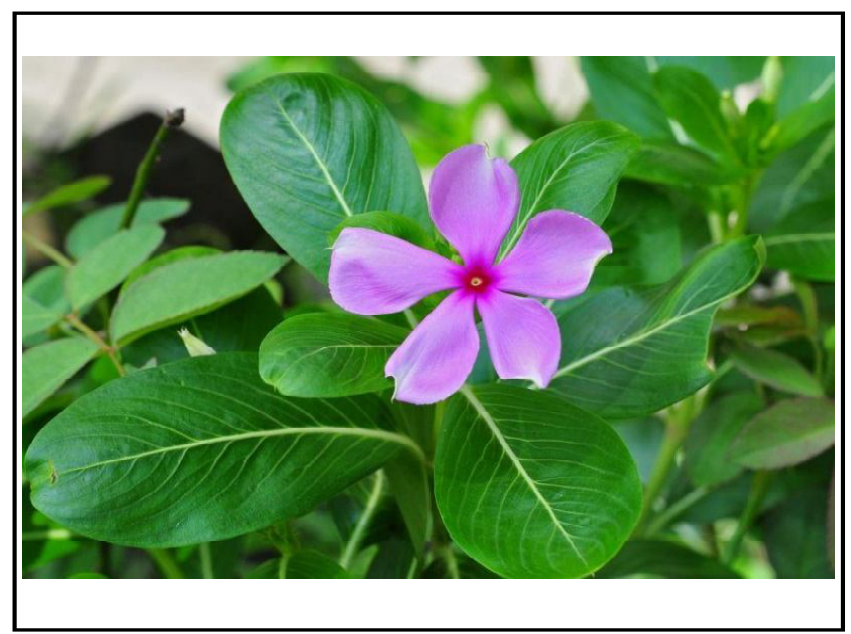

Figure 12: Catharanthus roseus L. (Mishra and Verma, 2012).

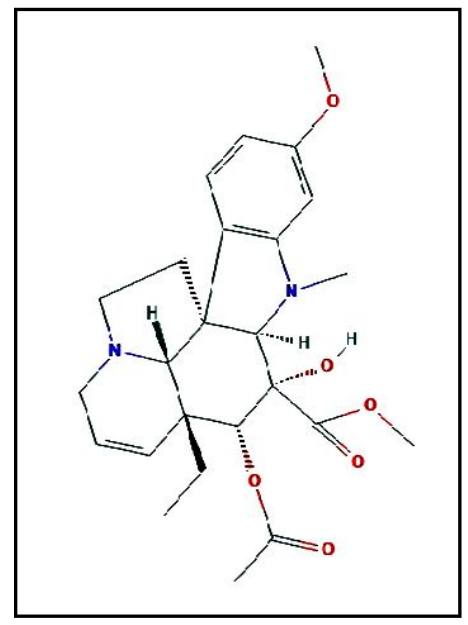

Figure 13: Structure of vindoline (NCBI, 2021).

\subsubsection{Mode of action}

The mechanism of action enhances insulin synthesis from the $\beta$ cells of Langerhans (Rahimi, 2015). It exerts antidiabetic activity by improving intestinal glucose absorption through glucose-6phosphate dehydrogenase activity in the pentose phosphate pathway (Choudhury et al., 2018; Tiong et al., 2015; Singh et al., 2001).

\subsection{Trigonella-foenum graecum $\mathbf{L}$.}

It is commonly known as fenugreek and belongs to the genus Fabaceae as an annual aromatic herb. Trigonelline, secondary metabolite, mucilage, and other various compounds which are available in dried ripe seed of plants are being utilised for medicinal purpose (Governa et al., 2018; WHO, 2007). Diosgenin (3b- 
hydroxy-5-spirostene), 4-hydroxyisoleucine (figure 2), and the soluble dietary fibre fraction are the most researched fenugreek bioactive compounds with reported hypoglycemic activities (Fuller and Stephens, 2015).

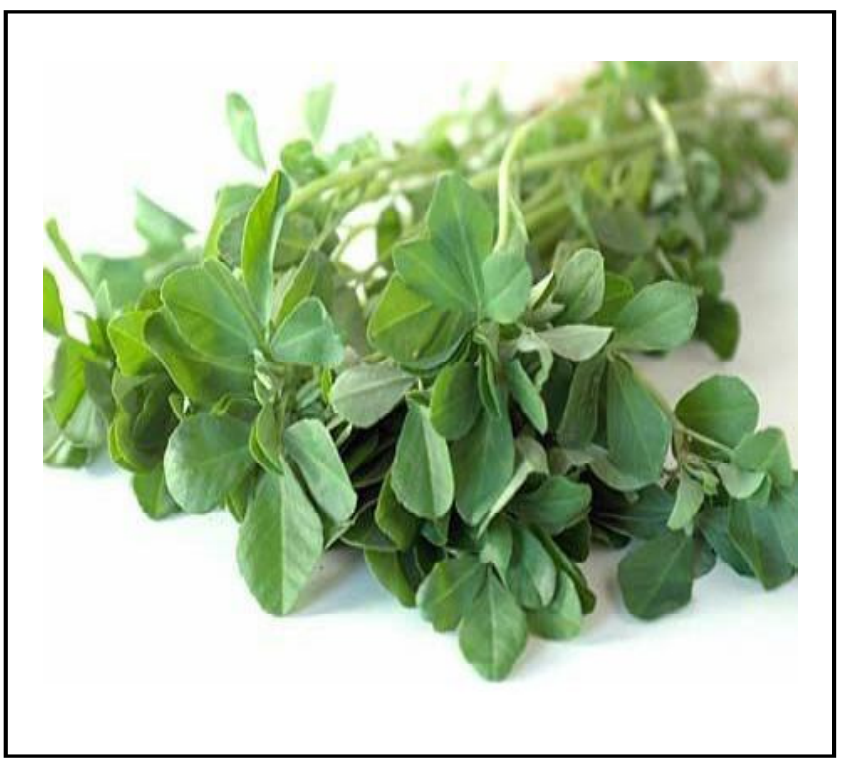

Figure 14: Trigonella foenum-graecum herb (Branch, 2013).

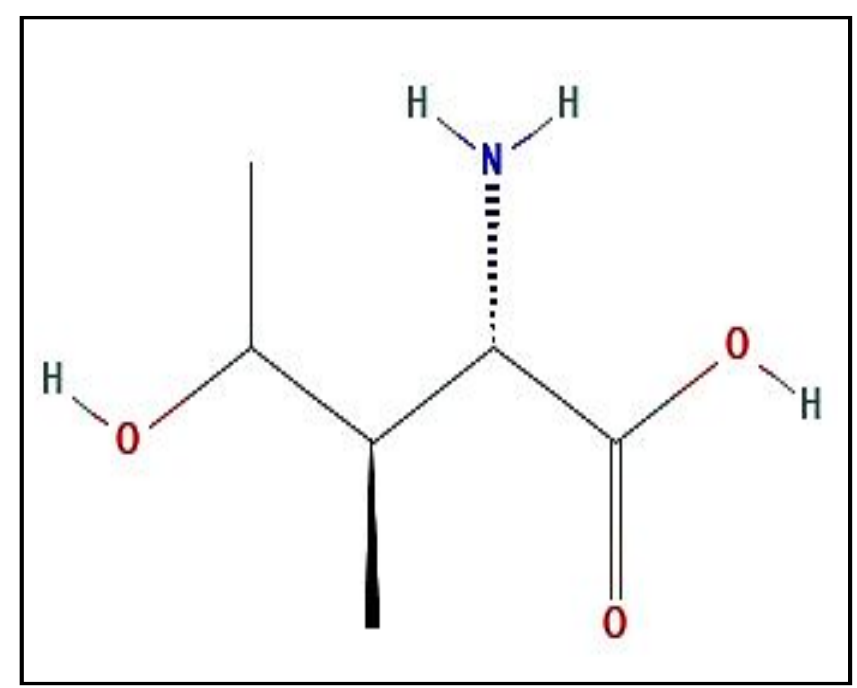

Figure 15: Structure of 4-hydroxyisoleucine (NCBI, 2021).

\subsubsection{Mode of action}

Diosgenin is a major aglycone of saponin in fenugreek, and its recorded hypoglycemic action include renewal of pancreatic $\beta$-cell and insulin secretion stimulation (Kalailingam et al., 2014), antioxidant effects (Son et al., 2007), and the promotion of insulindependent glucose uptake and adipocyte differentiation promotion (Uemura et al., 2010). Fenugreek seeds (5-100 g/day) have been found to be a promising alternative for diabetes management. Indeed, this medication leads to improved glycemic regulation in type 2 diabetes mellitus patients (Nahas and Moher, 2009; Shojaii et al., 2011; Suksomboon et al., 2011; Neelakantan et al., 2014).

\section{Future scenario of medicinal plants for treatment of diabetes mellitus}

Individuals use a variety of herbal remedies, and various indigenous medications are regularly introduced into modern therapeutics. For healthcare, approximately $80 \%$ of the population, especially rural people belong to developing countries, rely on traditional medical remedies. There has been a surge in interest in phytomedicine in developing countries, owing to the popularity of a large number of products derived from natural sources. There is also a distinction to be made between herbal medicines prescribed by a physician and herbal remedies that are readily available for self-medication. The discovery of plants that could be beneficial to people with antidiabetic activity has gotten a lot of attention in recent years (Verma et al., 2018; Rosalie and Ekype, 2016).

\section{Conclusion}

Diabetes mellitus has no permanent remedy, the treatment depends on the antidiabetic medications in the market, but their long-term use leads to several side effects which is the main problem with these drugs. Despite the availability of antidiabetic drugs in the pharmaceutical industry, medicinal plant treatment for diabetes is effective. Notable medicinal plant components and herbal remedies with low toxicity and no side effects are common options for diabetes care around the world.

In the design of medication and treatment of hyperglycemic problems in diabetes mellitus, substances and extracts from a variety of natural resources play a critical role. It can be concluded that for the treatment or prevention of diabetes mellitus, medicinal plants with antidiabetic activity can be regarded as substitute or adjunctive medicines.

Medicinal plants compound does not work only on one aspect to cure, but acts at different pathways and molecules to reduce overall high glucose concentration and its effect on other tissues. However, it is important to research the effects of medicinal plants on DM in detail in order to obtain further data on the biological and pharmacological effects of these plants.

\section{Conflict of interest}

The authors declare that there are no conflicts of interest relevant to this article.

\section{References}

Aderibigbe, A.O.; Emudianughe, T.S. and Lawal, B.A.S. (1999). Antihyperglycaemic effect of Mangifera indica in rat. Phytotherapy research: An International Journal Devoted to Pharmacological and Toxicological Evaluation of Natural Product Derivatives, 13(6): 504-507.

Aderibigbe, A.O.; Emudianughe, T.S. and Lawal, B.A.S. (2001). Evaluation of the antidiabetic action of Mangifera indica in mice. Phytotherapy Research, 15(5):456-458.

Ahangarpour, A. and Oroojan, A.A. (2013). Effect of crust and seed hydroalcoholic and aqueous extracts and pulp hydroalcoholic extract of Citrullus colocynthis on glucose, insulin and FIRI level in insulin resistant male rats. The Horizon of Medical Sciences, 19(3):149-154.

Andrade-Cetto, A. and Wiedenfeld, H. (2004). Hypoglycemic effect of Acosmium panamense bark on streptozotocin diabetic rats. Journal of Ethnopharmacology, 90(2-3):217-220. 
Barghamdi, B.; Ghorat, F.; Asadollahi, K.; Sayehmiri, K.; Peyghambari, R. and Abangah, G. (2016). Therapeutic effects of Citrullus colocynthis fruit in patients with type II diabetes: A clinical trial study. Journal of Pharmacy and Bioallied Sciences, 8(2):130.

Bayan, L.; Koulivand, P.H. and Gorji, A. (2014). Garlic: a review of potential therapeutic effects. Avicenna Journal of Phytomedicine, 4(1):1.

Beccuti, G.; Monagheddu, C.; Evangelista, A.; Ciccone, G.; Broglio, F.; Soldati, L. and Bo, S. (2017). Timing of food intake: Sounding the alarm about metabolic impairments? A systematic review. Pharmacological Research, 125:132-141.

Bhatia, V.K.; Ramanathan, J.D. and Seshadri, T.R. (1967). Constitution of mangiferin. Tetrahedron, 23(3):1363-1368.

Branch, S. (2013). Fenugreek (Trigonella foenum-graecum L.) as valuable medicinal plant. International Journal of Advanced Biological and Biomedical Research, 1(8):922-931.

Chaturvedi, P. (2012). Antidiabetic potentials of Momordica charantia: multiple mechanisms behind the effects. Journal of Medicinal Food, 15(2):101-107.

Choudhury, H.; Pandey, M.; Hua, C.K.; Mun, C.S., Jing, J.K.; Kong, L. and Kesharwani, P. (2018). An update on natural compounds in the remedy of diabetes mellitus: A systematic review. Journal of Traditional and Complementary Medicine, 8(3):361-376

Desai, P.D.; Dutia, M.D.; Ganguly,A.K.; Govindachari, T.R.; Joshi, B.S.; Kamat V.N. and Viswanathan, N. (1967). Chemical investigation of some Indian plants. Part III. Indian Journal of Chemistry, 5(10):523524

Dwivedi, C. and Daspaul, S. (2013). Antidiabetic herbal drugs and polyherbal formulation used for diabetes: A review. Journal of Phytopharmacology, 2(3):44-51

Ehrlich, S.D. (2013). Herbal Medicine. University of Maryland Medical Center.

El Ansari, M.A.; Rajadurai, S. and Nayudamma, Y. (1967). Studies on the polyphenols of Mangifera indica bark. Leather Science, 14:24751 .

El Ansari, M.A.; Reddy, K.K.; Sastry, K.N.S. and Nayudamma, Y. (1971). Polyphenols of Mangifera indica Phytochemistry, 10(9):22392241

Eldin, I.M.T.; Ahmed, E.M. and Abd, E.H. (2010). Preliminary study of the clinical hypoglycemic effects of Allium cepa (red onion) in type 1 and type 2 diabetic patients. Environmental Health Insights, 4: EHI-S5540.

Elgerwi, A.A.; Benzekri, Z.; El-Magdoub, A. and El-Mahmoudy, A. (2013) Qualitative identification of the active principles in Citrullus colocynthis and evaluation of its teratogenic effects in albino rats. International Journal of Basic and Clinical Pharmacology, 2(4):438-445.

Forbes, J.M. and Cooper, M.E. (2013). Mechanisms of diabetic complications. Physiological Reviews, 93(1):137-188.

Fuller, S. and Stephens, J.M. (2015). Diosgenin, 4-hydroxyisoleucine, and fiber from fenugreek: Mechanisms of actions and potential effects on metabolic syndrome. Advances in Nutrition, 6(2):189-197.

Ganie, M.A. and Kotwal, S. (2012). Recent advances in management of diabetes mellitus. Journal of International Medical Sciences Academy, 25(3):171-175.

Gebreyohannes, G. and Gebreyohannes, M. (2013). Medicinal values of garlic: A review. International Journal of Medicine and Medical Sciences, 5(9):401-408.
Gill, N.S.; Kaur, S.; Arora, R. and Bali, M. (2011). Screening of antioxidant and antiulcer potential of Citrullus colocynthis methanolic seed extract. Research Journal of Phytochemistry, 5(2):98-106.

Giovannini, P.; Howes, M.J.R. and Edwards, S.E. (2016). Medicinal plants used in the traditional management of diabetes and its sequelae in Central America: A review. Journal of Ethnopharmacology, 184: $58-71$.

Governa, P.; Baini, G.; Borgonetti, V.; Cettolin, G.; Giachetti, D.; Magnano, A.R. and Biagi, M. (2018). Phytotherapy in the management of diabetes: A review. Molecules, 23(1):105.

Grover, J.K. and Yadav, S.P. (2004). Pharmacological actions and potential uses of Momordica charantia: A review. Journal of Ethnopharmacology, 93(1):123-132.

Iciek, M.; Kwiecień, I. and Włodek, L. (2009). Biological properties of garlic and garlic derived organosulfur compounds. Environmental and Molecular Mutagenesis, 50(3):247-265.

Jayaraman, R. and Christina, A.J.M. (2013). Evaluation of Citrullus colocynthis fruits on in vitro antioxidant activity and in vivo DEN/PB induced hepatotoxicity. International Journal of Applied Research in Natural Products, 6(1):1-9.

Jevas, C. (2011). Antidiabetic effects of Allium cepa (onions) aqueous extracts on alloxan-induced diabetic Rattus novergicus. Journal of Medicinal Plants Research, 5(7):1134-1139.

Joseph, B. and Jini, D. (2013). Antidiabetic effects of Momordica charantia (bitter melon) and its medicinal potency. Asian Pacific Journal of Tropical Disease, 3(2):93-102.

Jurez-Rojop, I.E.; Diaz-Zagoya, J.C.; Ble-Castillo, J.L.; Miranda-Osorio, P.H.; Castell-Rodrguez, A.E. and Tovilla-Zrate, C.A. (2012). Hypoglycemic effect of Carica papaya leaves in streptozotocin-induced diabetic rats. BMC Complementary and Alternative Medicine, 12:236.

Kalailingam, P.; Kannaian, B.; Tamilmani, E. and Kaliaperumal, R. (2014). Efficacy of natural diosgenin on cardiovascular risk, insulin secretion, and beta cells in streptozotocin (STZ)-induced diabetic rats. Phytomedicine, 21(10):1154-1161.

Khan, M.Y.; Aziz, I.; Bihari, B.; Kumar, H.; Roy, M. and Verma, V.K. (2014). A review-Phytomedicines used in treatment of diabetes. Asian Journal of Pharmaceutical Research, 4(3):135-154.

Kouadri, I.; Layachi, A.; Makhlouf, A. and Satha, H. (2018). Optimization of extraction process and characterization of water-soluble polysaccharide (Galactomannan) from Algerian biomass; Citrullus colocynthis seeds. International Journal of Polymer Analysis and Characterization, 23(4):362-375.

Krishna, K.L.; Paridhavi, M. and Patel, J. A. (2008). Review on nutritional, medicinal and pharmacological properties of Papaya (Carica papaya Linn.). Natural Product Radiance, 7(4):364-373.

Lakshmi, M.S.; Rani, S.K. and Reddy, T. (2012). A review on diabetes mellitus and the herbal plants used for its treatment. Asian Journal of Pharmaceutical and Clinical Research, 5(4):15-21.

Li, W.; Yuan, G.; Pan, Y.; Wang, C. and Chen, H. (2017). Network pharmacology studies on the bioactive compounds and action mechanisms of natural products for the treatment of diabetes mellitus: A review. Frontiers in Pharmacology, 8:74.

Malvi, R.; Jain, S.; Khatri, S.; Patel, A. and Mishra, S. (2011). A review on antidiabetic medicinal plants and marketed herbal formulations. International Journal of Pharmaceutical and Biological Archive, 2:1344-1355. 
Mishra, J.N. and Verma, N.K. (2017). A brief study on Catharanthus roseus: A review. Internation Journal of Research in Pharmacy and Pharmaceutical Sciences, 2(2):20-23.

Nahas, R. and Moher, M. (2009). Complementary and alternative medicine for the treatment of type 2 diabetes. Canadian Family Physician, 55(6):591-596.

Najafi, S.; Sanadgol, N.; Nejad, B.S.; Beiragi, M.A. and Sanadgol, E. (2010). Phytochemical screening and antibacterial activity of Citrullus colocynthis (Linn.) Schrad against Staphylococcus aureus. Journal of Medicinal Plants Research, 4(22):2321-2325.

National Center for Biotechnology Information (2021). PubChem Compound Summary for CID 10731, Anthranol. Retrieved April 2, 2021 from https://pubchem.ncbi.nlm.nih.gov/compound/Anthranol.

National Center for Biotechnology Information (2021). PubChem Compound Summary for CID 5281647, Mangiferin. Retrieved April 2, 2021 from https://pubchem.ncbi.nlm.nih.gov/compound/Mangiferin.

National Center for Biotechnology Information (2021). PubChem Compound Summary for CID 16591, Allyl propyl disulfide. Retrieved April 2, 2021 from https://pubchem.ncbi.nlm.nih.gov/compound/Allylpropyl-disulfide.

National Center for Biotechnology Information (2021). PubChem Compound Summary for CID 5280489, beta-Carotene. Retrieved April 2, 2021 from https://pubchem.ncbi.nlm.nih.gov/compound/betaCarotene.

National Center for Biotechnology Information (2021). PubChem Compound Summary for CID 260535, Vindoline. Retrieved April 2, 2021 from https://pubchem.ncbi.nlm.nih.gov/compound/260535.

National Center for Biotechnology Information (2021). PubChem Compound Summary for CID 87310, 3-(Allylsulphinyl)-L-alanine. Retrieved March 12, 2021 from https://pubchem.ncbi.nlm.nih.gov/ compound/3-_Allylsulphinyl_-L-alanine.

National Center for Biotechnology Information (2021). PubChem Compound Summary for CID 2773624, 4-Hydroxyisoleucine. Retrieved March 12, 2021 from https://pubchem.ncbi.nlm.nih.gov/ compound/4 - Hydroxyisoleucine.

Neelakantan, N.; Narayanan, M.; de Souza, R.J. and van Dam, R.M. (2014). Effect of fenugreek (Trigonella foenum graecum L.) intake on glycemia: a meta-analysis of clinical trials. Nutrition Journal, 13(1):1-11.

Nmila, R.; Gross, R.; Rchid, H.; Roye, M.; Manteghetti, M.; Petit, P. and Sauvaire, Y. (2000). Insulinotropic effect of Citrullus colocynthis fruit extracts. Planta Medica, 66(05):418-423.

Nuss, J.M. and Wagman, A.S. (2000). Recent advances in therapeutic approaches to type 2 diabetes. pp:211-220.

Ota, A. and Ulrih, N.P. (2017). An overview of herbal products and secondary metabolites used for management of type two diabetes. Frontiers in Pharmacology, 8:436.

Padiya, R. and K Banerjee, S. (2013). Garlic as an antidiabetic agent: recent progress and patent reviews. Recent Patents on Food, Nutrition and Agriculture, 5(2):105-127.

Parvez, G.M. (2016). Pharmacological activities of mango (Mangifera indica): A review. Journal of Pharmacognosy and Phytochemistry, 5(3): 1 .

Rahimi, M. (2015). A review: antidiabetic medicinal plants used for diabetes mellitus. Bulletin of Environment, Pharmacology and Life Sciences, 4(2):163-180.
Rodge, S.V. and Biradar, S.D. (2012). Preliminary Phytochemical screening and antimicrobial activity of Citrullus colocynthis (Linn.) Shared. Indian Journal of Plant Sciences, 2(1):19-23.

Rosalie, I.O. and Ekype, E.L. (2016). Antidiabetic potentials of common herbal plants and plant products: A glance. International Journal of Herbal Medicine, 4(4):90-97.

Shibib, B.A.; Khan, L.A. and Rahman, R. (1993). Hypoglycaemic activity of Coccinia indica and Momordica charantia in diabetic rats: depression of the hepatic gluconeogenic enzymes glucose-6phosphatase and fructose-1, 6-bisphosphatase and elevation of both liver and red-cell shunt enzyme glucose-6-phosphate dehydrogenase. Biochemical Journal, 292(1):267-270.

Shojaii, A.; Hashem, D.F.; Goushegir, A. and Abdollahi, F.M. (2011). Antidiabetic plants of Iran. pp:637-642.

Singh, S.N.; Vats, P.; Suri, S.; Shyam, R.; Kumria, M.M.L.; Ranganathan, S. and Sridharan, K. (2001). Effect of an antidiabetic extract of Catharanthus roseus on enzymic activities in streptozotocin induced diabetic rats. Journal of Ethnopharmacology, 76(3):269-277.

Son, I.S.; Kim, J.H.; Sohn, H.Y.; Son, K.H.; Kim, J.S. and Kwon, C.S. (2007). Antioxidative and hypolipidemic effects of diosgenin, a steroidal saponin of yam (Dioscorea spp.), on high-cholesterol fed rats. Bioscience, Biotechnology, and Biochemistry, 71(12):30633071 .

Suksomboon, N.; Poolsup, N.; Boonkaew, S. and Suthisisang, C.C. (2011). Metaanalysis of the effect of herbal supplement on glycemic control in type 2 diabetes. Journal of Ethnopharmacology, 137(3):13281333.

Talole, B.; Bahet, G. and Waje, K. (2013). Pharmacognostic study of Citrullus colocynthis Linn Schard leaves. International Journal of Pharmacy and Pharmaceutical Sciences, 5(3):198-201.

Thomson, M.; Al-Qattan, K.K.; Divya, J.S. and Ali, M. (2015). Antidiabetic and antioxidant potential of aged garlic extract (AGE) in streptozotocin - induced diabetic rats. BMC Complementary and Alternative Medicine, 16(1):1-9.

Tiong, S.H.; Looi, C.Y.; Arya, A.; Wong, W.F.; Hazni, H.; Mustafa, M.R. and Awang, K. (2015). Vindogentianine, a hypoglycemic alkaloid from Catharanthus roseus (L.) G. Don (Apocynaceae). Fitoterapia, 102:182188 .

Tripathi, K.D. (2013). Essentials of medical pharmacology. JP Medical Ltd. pp:270-278.

Tropicos.org. Missouri Botanical Garden. 02 Apr $2021<\mathrm{http}: / / w w w$. tropicos.org/Image/67690> Photographer: B. Hammel CC-BYNC-SA.

Tsai, C.H.; Chen, E.C.F.; Tsay, H.S. and Huang, C.J. (2012). Wild bitter gourd improves metabolic syndrome: A preliminary dietary supplementation trial. Nutrition Journal, 11(1):1-9.

Uemura, T.; Hirai, S.; Mizoguchi, N.; Goto, T.; Lee, J. Y.; Taketani, K. and Kawada, T. (2010). Diosgenin present in fenugreek improves glucose metabolism by promoting adipocyte differentiation and inhibiting inflammation in adipose tissues. Molecular Nutrition and Food Research, 54(11):1596-1608.

Uma, C. and Sekar, K.G. (2014). Phytochemical analysis of a folklore medicinal plant Citrullus colocynthis L (bitter apple). Journal of Pharmacognosy and Phytochemistry, 2(6):195-202.

Upadhyay, R.K. (2016). Nutraceutical, pharmaceutical and therapeutic uses of Allium cepa: A review. International Journal of Green Pharmacy (IJGP), 10(1). 
Varisha, A.; Ansari, S.H.; Naquvi, K.J.; Poonam, A. and Adil, A. (2013). Development of quality standards of Carica papaya Linn. leaves. Der Pharmacia Lettre, 5(2):370-376.

Verma, S.; Gupta, M.; Popli, H. and Aggarwal, G. (2018). Diabetes mellitus treatment using herbal drugs. International Journal of Phytomedicine, 10(1):1-10

WHO Expert Consultation (2002). Report of the expert committee on the diagnosis and classification of diabetes mellitus. Diabetes Care, 25:5-20.

Wild, S.; Roglic, G. ; Green,A.; Sicree, R. and King, H. (2004). Global prevalence of diabetes: Estimates for the year 2000 and projections for 2030. Diabetes Care, 27(5):1047-1053.

World Health Organization. (1999). WHO monographs on selected medicinal plants (Vol. 2). World Health Organization.
World Health Organization. (2007). WHO monographs on selected medicinal plants (Vol. 3). World Health Organization.

Wu, Y.; Ding, Y.; Tanaka, Y. and Zhang, W. (2014). Risk factors contributing to type 2 diabetes and recent advances in the treatment and prevention. International Journal of Medical Sciences, 11(11): 1185.

Xu, L.; Li, Y.; Dai, Y. and Peng, J. (2018). Natural products for the treatment of type 2 diabetes mellitus: Pharmacology and mechanisms. Pharmacological Research, 130:451-465.

Xu, X.; Shan, B.; Liao, C.H.; Xie, J.H.; Wen, P.W. and Shi, J.Y. (2015). Antidiabetic properties of Momordica charantia L. polysaccharide in alloxaninduced diabetic mice. International Journal of Biological Macromolecules, 81:538-543.

Yuwai, K.E.; Rao, K.S.; Kaluwin, C.; Jones, G.P. and Rivett, D.E. (1991). Chemical composition of Momordica charantia L. fruits. Journal of Agricultural and Food Chemistry, 39(10):1762-1763.

Sanjeev Singh and Divya Singh (2021). Phytomedicine: Alternative safe vehicles on the pathway of Diabetes Mellitus. Ann. Phytomed., 10(1):114-122. http://dx.doi.org/10.21276/ap.2021.10.1.12 